\title{
RECRYSTALLIZATION AT GRAIN BOUNDARIES IN DEFORMED COPPER BICRYSTALS
}

\author{
H. W. F. HELLER $\dagger$, C. A. VERBRAAK $\ddagger$ and B. H. KOLSTER \\ Twente University of Technology, Department of Mechanical Engineering, Materials Section. Enschede, \\ The Netherlands
}

(Received 6 September 1983; in revised form 9 February 1984)

\begin{abstract}
Abetract-The role of specific grain boundaries in the nucleation of recrystallization textures is demonstrated by experiments on copper bicrystals. It is deduced that the major part of the recrystallized grains that have nucleated at the grain boundary can be traced back to having nucleated in $\{100\}\langle 001\rangle$, $\{210\}\langle 001\rangle$ or $\{210\}\langle 120\rangle$ orientations. These orientations do not exist in the bicrystals after deformation but can easily be accounted for by the $\langle 112\rangle$-slip nucleation mechanism proposed by Verbraak. X-ray strain measurements support this conclusion. Finally, on the basis of the observation of near-CSL misorientation relationships between deformed matrix and recrystallized grains, a suggestion is made for a more general nucleation mechanism.
\end{abstract}

Réount-Grâce à des expériences sur des bicristaux de cuivre, nous démontrons le rôle de joints de grains particuliers sur la germination des textures de recristallisation. On conclut que la plupart des grains recristallisés ayant germé sur le joint de grains avaient germé selon les orientations $\{100\}\langle 001\rangle$, $\{210\}\langle 001\rangle$ ou $\{210\}\langle 120\rangle$. Ces orientations n'existent pas dans les bicristaux après déformation, mais on peut en rendre comple par le mécanisme de germination par glissement (112) proposé par Verbraak. Des mesures de déformation par rayons $X$ confirment cette conclusion. Finalement. à partir de lobservation de relations de désorientations proches du réseau de sites de coincidence entre la matrice déformée et les grains recristallisés, nous proposons un mécanisme de germination plus général.

\begin{abstract}
Zmanmenfanme-Die Rolle spezifischer Korngrenzen bei der Keimbildung in Rekristallisationstexturen wird gezeigt mittels Versuche an Kupferbikristalle. Es wird deduziert dass, der grösste Teil der rekristallisierten Kömer, deren Keimbildung an der Korngrenze stattfand, zurück geführt werden kann auf Keimbildung in $\{100\}\langle 001\rangle,\{210\}\langle 001\rangle$ und $\{210\}\langle 120\rangle$ Orientierungen. Diese Orientierungen sind nicht in den deformierten Bikristallen anwesend aber sie können leicht erklärt werden mit Hilfe des Keimbildungsmechanismus mittels (112)-Gleitung, vorgeschlagen von Verbraak. Röntgenspannungsmessungen unterstützen diese Konklusion. Schliesslich, basiert auf das Vorhandensein der Koinzidenzgitter-Fehlorientierungsbeziehungen zwischen deformiertem Material und rekristallisierten Körner. wird einen allgemeineren Keimbildungsmechanismus vorgeschlagen.
\end{abstract}

\section{INTRODUCTION}

The normal process of recrystallization of deformed metals is the formation of new nearly defect-free crystals and the growth of these into the surrounding deformed metal. Thus nucleation and grain-growth processes are involved. The problem of the transformation of deformation textures into recrystallization textures has been tackled in the past $\mathbf{5 0}$ years in two different ways: (i) the solution must be found in the nucleation of recrystallization textures, and (ii) the solution must be found in the growth of newly developed grains rather than in the nucleation event itself. This approach has been embodied in the contradictory theories of "oriented nucleation" and "oriented growth".

In this paper the nucleation point of view has been taken as the basis for experiments on copper bicrystals.

†Present address: N. V. Kema, Division WSK, Utrechteeweg 310, Amhem, The Netherlands.

$\$$ Professor Dr Ir. C. A. Verbraak passed away on the 23 March 1983.
If oriented nucleation accounts for the transformation of deformation textures into recrystallization textures, one of the following conditions must be met: either

(i) matrix regions with orientations identical to those observed in the recrystallization texture must preferentially nucleate by an appropriate nucleation mechanism that transforms these regions into viable nuclei; nucleation mechanisms like transition-band nucleation [3.4] and nucleation by bulging out of pre-existing grain boundaries [5] are representative examples of nucleation in this way; or

(ii) nucleation mechanisms must exist that can form viable nuclei with completely new orien. tations in case the matrix does not include eiements with orientations of the recrystallization texture; annealing twin formation $[6,7]$ is a widely accepted example of such a nucleation mechanism.

Due to a choice between these conditions the formation of the cube recrystallization texture in polycrystalline aluminium and copper has occasioned 
much brain-racking, since pole-figure measurements by X-ray diffraction show no traces of cube components after deformation. Consequently, a nucleation mechanism was proposed by Verbraak [1.2] that could explain the formation of the cube recrystallization texture in copper. In this martensitic type of nucleation mechanism an incoherent twin boundary was predicted to be a possible nucleation site for cube and off-cube orientations. Ever since, the theoretical aspects of this mechanism and, above all, the probability of occurrence were under discussion, but did not lead to a general acceptance of the mechanism.

In recent extensive electron-microscopical studies traces of cube-oriented deformed cells have been reported, in which several nucleation mechanisms were suggested for the development of recrystallization nuclei: nucleation by subboundary migration or boundary-bulging mechanisms $[8,9]$, nucleation by coalescence [10], and preferred nucleation due to rapid recovery [11]. These observations are in accordance with the first condition described above, whereas the $\langle 112\rangle$-slip nucleation mechanism as proposed by Verbraak obeys the second condition. In both cases appropriate structural arrangements must exist to develop cube-oriented nuclei, that is local high lattice distortion (e.g. transition bands) and specific grain boundaries respectively.

The role of specific grain boundaries in the nucleation process may, however, best of all be investigated in bicrystals, since well defined orientations and grain boundaries can be chosen. To that end, recrystallization experiments were carried out on deformed copper bicrystals.

In order to make the results on bicrystals applicable to polycrystalline copper, the orientations of the two components must be chosen from components of the texture of cold rolled polycrystalline copper. Thus, the bicrystal parts should have orientations of the main components of the copper-deformation texture, that is combinations of $\{112\}\langle 111\rangle$, $\{110\}\langle 112\rangle$, and $\{123\}\langle 412\rangle$ orientations. The final choice of orientations was made in such a way that conditions were fulfilled for the verification of a nucleation mechanism resulting from cooperative (112) slip. These considerations led to two series of experiments, in which the recrystallization is studied in twin-oriented $\{112\}\langle 111\rangle$ bicrystals and twinoriented $\{110\}<112\rangle$ bicrystals.

\section{EXPERIMENTAL}

The bicrystals for the experiments were obtained from the Technische Universität Clausthalt, FRG. The material used was zone-refined copper with a purity of $99.9998 w t \%$. The crystals were made by the Bridgman method, using a split graphite mould in a

†Institut für Metallkunde und Metallphysik, Abteilung Werkstoffprüfung.
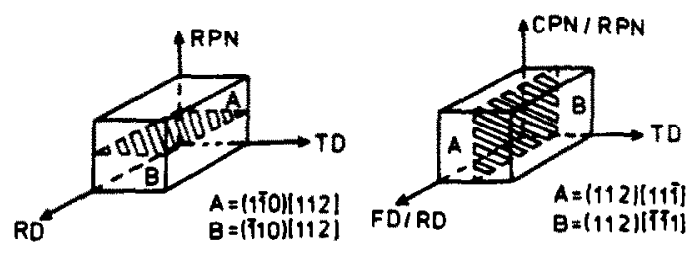

Fig. 1. Deformation geometry of $\{110\}\langle 112\rangle$ and $\{112\}\langle 111\rangle$ bicrystals.

vertical oven. The final preparation of the crystals in the required orientations was done by spark erosion. Figure 1 shows the deformation geometry of the bicrystals. In both cases the grain boundary was an incoherent (110) twin boundary.

In one series the crystals had the initial orientations (112)[11I]/(112)[II1], in the other series the orientations (110)[112]/(I10)[112] which were determined by standard Laue-methods (orientations were correct within $2^{\circ}$ ). The boundary plane in one series is parallel to the transversal plane and in the other series parallel to the rolling plane.

The dimensions of all crystals before deformation were about $10 \times 10 \times 12 \mathrm{~mm}^{3}(1 \times w \times h)$. In either series the deformation was achieved in two different ways: (i) plane-strain deformation performed in a specially constructed die and anvil by means of an MTS closed-loop testing system, displacement controlled (displacement $0.5 \mathrm{~mm} \mathrm{~min}^{-1}$ ) and (ii) deformation by rolling the specimens embedded in $10 \%$ deformed polycrystalline copper. The rolling was performed on a Buehler rolling mill (roll diameter $160 \mathrm{~mm}$ ), with reductions per pass chosen in such a way that the shape factor $L / d$ was approximately $\mid\left(L / d=\sqrt{R\left(d_{0}-d\right) / d_{0}}\right.$, with $R=$ roll radius, $d_{0}=$ entrance thickness, $d=$ exjt thickness. The specimens were rotated $180^{\circ}$ about the rolling direction (RD) between passes. In all cases the final reductions amounted to $40-60 \%$.

For orientation measurements after deformation pole figures were taken from several planes with a Philips back-reflection goniometer; $\mathrm{Co}_{\mathrm{K}} \mathrm{K}_{\mu}$ radiation was used. Measurements were corrected for defocusing up to $85^{\circ}$ inclination.

The structure and orientation present near the grain boundaries were also investigated with the electron-microscope. These investigations were carried out in a Philips E. M. 300 microscope, operating at $100 \mathrm{kV}$ accelerating voltage, and in a Jeol $200 \mathrm{CX}$ microscope, operating at $200 \mathrm{kV}$. Specimens for electron microscopy were cut from the crystals with a diamond saw and polished mechanically and electrochemically to a final thickness of $0.1-0.2 \mathrm{~mm}$.

In the deformed specimens there appeared to be no preferential polishing effect at the grain boundary. Therefore a sort of window technique was applied, in which the specimen was thinned in such a way that the transparent part contained the grain boundary. The thinning was done in a solution of $50 \mathrm{ml} \mathrm{H} \mathrm{O}_{2}$, $30 \mathrm{ml} \mathrm{H} \mathrm{PO}_{4}$, and $20 \mathrm{ml} \mathrm{H}_{2} \mathrm{O}$, heated at $40-50^{\circ} \mathrm{C}$. 
Because the surface of the specimens was etched in this solution, they were thereupon shortly electrochemically polished in a Struers D2 solution.

In optical microscopy the microstructure was revealed by etching in a $\mathrm{FeCl}_{3}$ solution in aethanol or etching in a saturated $\mathrm{Na}_{2} \mathrm{~S}_{2} \mathrm{O}_{3}\left(5 \mathrm{H}_{2} \mathrm{O}\right)$ solution diluted with $30 \% \mathrm{H}_{2} \mathrm{O}$. The specimens were previously mechanically and subsequently electrochemically polished in a Struers D2 solution.

Heat treatments were given in an air-circulation oven. The recrystallization was started with annealing treatments at temperatures varying between 320 and $400^{\circ} \mathrm{C}$ and for annealing times of $15-450 \mathrm{~s}$ (details are given when the results are discussed).

The orientations of the recrystallized grains developed after these treatments were measured with a micro-Laue technique. The use of a lead glass capillary collimator with a diameter of $10 \mu \mathrm{m}$ permitted orientation measurements in regions with a minimum size of $20 \mu \mathrm{m}$. The positioning could be performed with an accuracy better than $2 \mu \mathrm{m}$ [12]. Finally, the orientations were calculated with a computer program. The computed orientations had an accuracy of approximately $2^{\circ}$.

\section{RESULTS}

\subsection{The deformed state}

3.1.1. Pole figure measurements. From the investigations on the bicrystals with orientations $\{112\}\langle 111\rangle$ the results of two experiments will be discussed.

Figure 2 shows the $\{111\}$ pole figure of a bicrystal deformed by embedded rolling; The deformation amounts to $49.8 \%$. The spread in orientation about the separate initial bicrystal orientations can be observed, as the pole figure is taken from the rolling plane (see deformation geometry). A similar picture

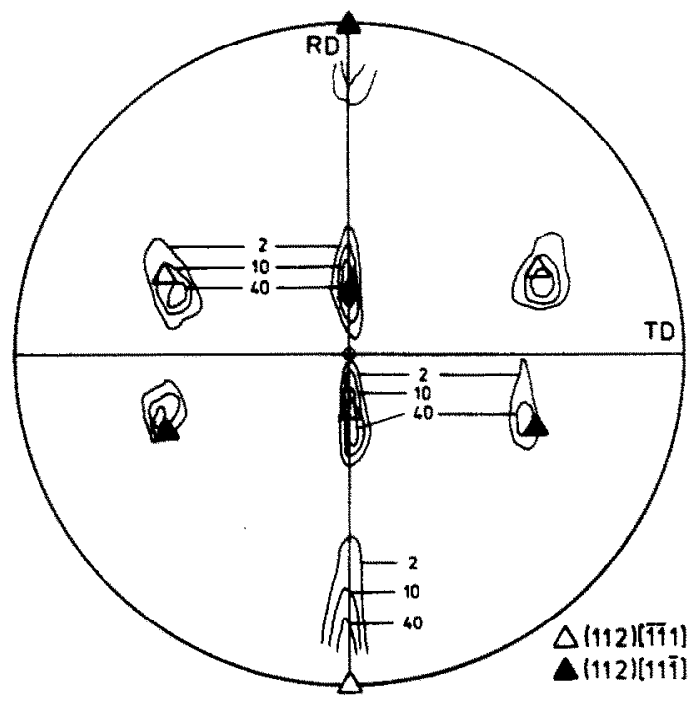

Fig. 2. $\{111\}$ pole figure of rolled $\{112\}\langle 111\rangle$ bicrystal, deformation $49.8 \%$.

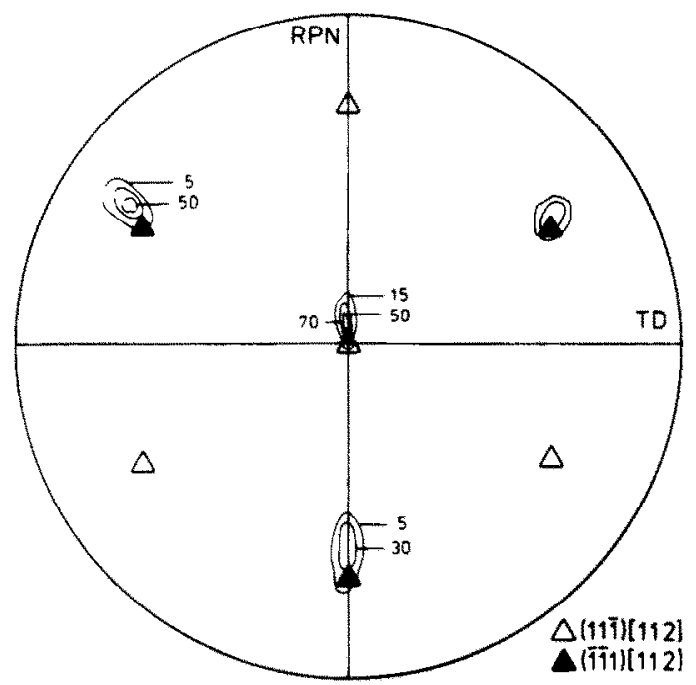

Fig. 3. $\{111\}$ pole figure of one part of rolled $\{112\}\langle 111\rangle$ bicrystal; pole figure taken from plane perpendicular to rolling direction.

is obtained from the $\{111\}$ pole figure of a plane strain deformed bicrystal; the total reduction in this case amounts to $41.6 \%$. Both bicrystals show a spread in orientation of approximately $10^{\circ}(5 \%$ of the maximum intensity) about the initial orientations, which can be described by a rotation mainly about the transversal $\langle 110\rangle$ direction. In the case of plane strain deformation the spread in orientation is smaller.

From pole-figure measurements on transversal planes and planes perpendicular to the rolling $\mathrm{c.q}$. free direction (RD c.q. FD) the texture proved to be homogeneous over the thickness of the crystal. Figure 3 , for instance, shows a pole figure, taken from the plane perpendicular to $R D$, of the rolled $\{112\}\langle 111\rangle$ bicrystal, with one bicrystal part covered with lead (the indices of the orientations with respect to this plane are (11T)[112] and (IT1)[112]. It is seen that one of the twinned orientations completely has disappeared. Texture inhomogenity in $\{112\}\langle 111\rangle$ crystals is often seen to be the development of its very twin component; see, for instance, Bauer et al. [13].

Texture homogeneity and a spread about the original components is also observed in the twinned $\{110\}\langle 112\rangle$ deformed bicrystals. A reduction of $57.5 \%$ was imposed in either case. Figure 4 gives a (111\} pole figure of a rolled crystal. The plane from which this pole figure was taken is perpendicular to the rolling direction, so the orientations described in this plane are (112)[II1] and (112)[11I]. Pole figures measured on the rolling c.q. compression plane suggest that the orientation spread of approximately $10^{\circ}$ is both about an axis near the transversal direction and about the $\langle 110\rangle$ rolling c.q. compression plane normal. The spread in orientation is similar in either case.

3.1.2. Electron-microscopical observations. While pole-figure measurements yielded an overall view of 


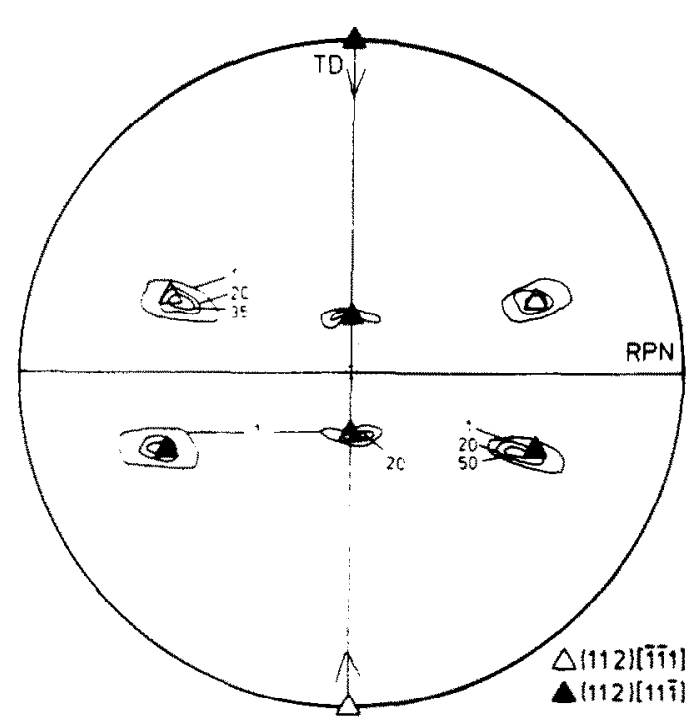

Fig. 4. $\{111\}$ pole figure of rolled $\{110\}\langle 112\rangle$ bicrystal (deformation $57.5^{\circ}$ ): pole figure taken from plane perpendicular to rolling direction.

the texture throughout the whole crystal, the electron-microscopical investigations were focused at studying structure and orientations near the grain boundary.

The photograph in Fig. 5 shows a representative bright-field image of a specimen of the $\{112\}\langle 111\rangle$ rolled bicrystal. The foil is transmitted parallel to the RD of the deformed crystal, so the primary beam is approximately parallel to the $\langle 111\rangle$ RD directions. It will be clear from this photograph that an elongated cell structure has been formed as a result of deformation. The longitudinal direction of these cells is parallel to the rolling plane and perpendicular to the grain boundary, as could be expected from the deformation geometry.

A summary of the orientations determined by selected area diffraction (SAD) is given in Table 1. The individual orientations belong to individual subgrains in the cell structure. The table only lists orientations that were measured at one side of the boundary. The orientations are permutated to rolling geometry. In order to visualize the orientations, their (111) poles are plotted in a stereographic projection in Fig. 6. The observed spread of the $\langle 111\rangle$ poles perfectly matches the spread about the (112)[11T] orientation in the $\{111\}$ pole figure (Fig. 2). Orientation measurements on the other side of the boundary yielded a similar spread in orientations about its (112)[TI1] twin orientation.

In a specimen of the $\{110\}\langle 112\rangle$ rolled bicrystal the structural features are of the same nature. Subgrains, however, are parallel to the boundary, as a consequence of the deformation geometry. A brightfield image of an area containing the grain boundary is presented in Fig. 7. The selected-area diaphragm for the SAD pattern overlapped the grain boundary. The normal to the foil is parallel to the RD; the grain

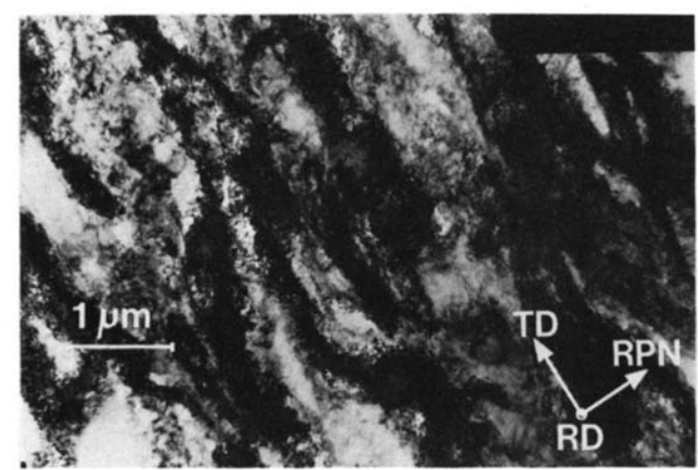

Fig. 5. Bright-field TEM image of plane perpendicular to rolling direction of rolled $\{112\}\langle 111\rangle$ bicrystal.

boundary plane is therefore approximately perpendicular to the foil surface (see deformation geometry).

From the SAD pattern and the width of the fringes it can be deduced that the boundary plane is still very near to a $\{110\}$ plane (boundary plane inclination is $85^{\circ}$ ). The SAD pattern further shows that in this part of the grain boundary the original twinned $\{112\}\langle 111\rangle$ orientations (in rolling geometry $\{110\}\langle 112\rangle)$ are present with only a slight rotation (approximately $4^{\circ}$ ) about the $\langle 112\rangle$ RD (central spot in the SAD pattern). Figure 8 presents a stereographic projection with $\langle 111\rangle$ poles of the observed orientations. There is no need to distinguish between orientations measured very near to the grain boundary and those measured at some distance, because the same differences were measured in either case.

The $\langle 111\rangle$-pole plot can be compared with the \{111\} pole figure (Fig. 4). The major part of the orientation spreads in both figures are again in good agreement, because they are overlapping. A small number of $\langle 111\rangle$ poles in the plot lie, however, just outside the spread of the $\langle 111\rangle$ poles in the pole figure. This phenomenon indicates that on microscale

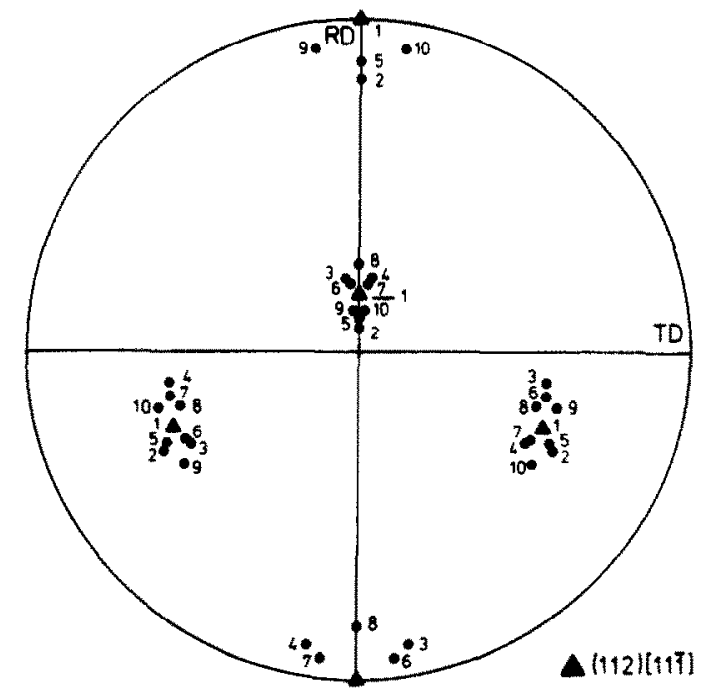

Fig. 6. Stereographic projection showing $\langle 111\rangle$ poles of orientations from Table 1 . 


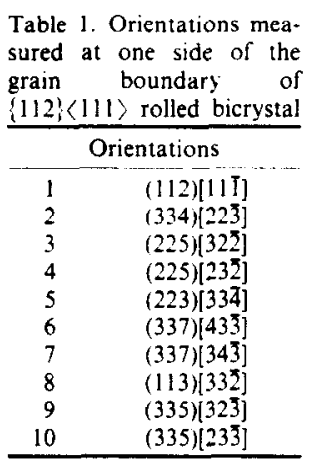

slightly larger orientation differences can exist than the pole-figure measurements suggest.

In conclusion, it can be stated that in all bicrystals deformation brings about a small orientation spread about the initial orientations by formation of subgrains. This spread is in good agreement with pole figure measurements.

Finally, these electron-microscopical investigations did not reveal a difference in structure and orientation between the grain-boundary region and the matrices themselves.

\subsection{The recrystallized state}

Annealing temperatures and times were chosen in such a way that the early start of the recrystallization could be studied. Especially in the $\{112\}\langle 111\rangle$ bicrystals the heat treatments were found to cause nucleation of recrystallized grains not only at the grain boundary but also in the matrix. Apparently, the grain boundary is not a pre-eminent nucleation site in these cases. The photograph in Fig. 9 clearly demonstrates this behaviour; the example shown is a specimen of the $\{112\}<111\rangle$ rolled bicrystal that has been annealed for $15 \mathrm{~s}$ at $400 \mathrm{C}$.

Nevertheless, nucleation at the grain boundary is observed to such an amount as to be considered as a significant feature in the recrystallization process. The photograph in Fig. 10 shows the annealed struc-

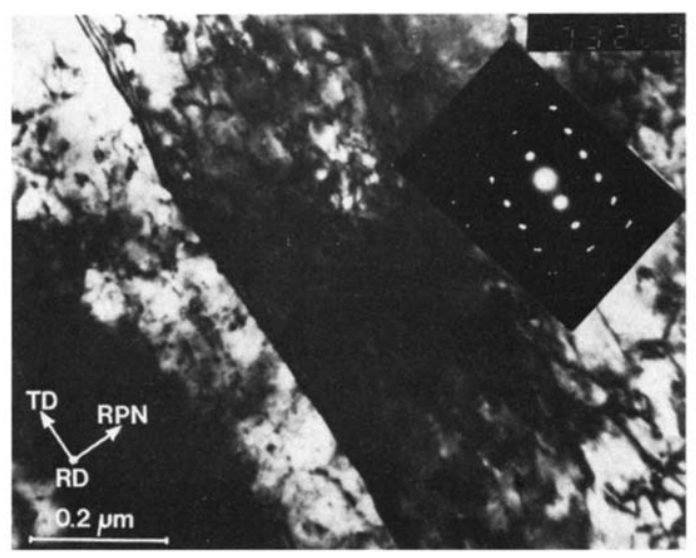

Fig. 7. Bright-field TEM image and diffraction pattern of plane perpendicular to rolling direction of $\{110\}\langle 112\rangle$ rolled bicrystal.

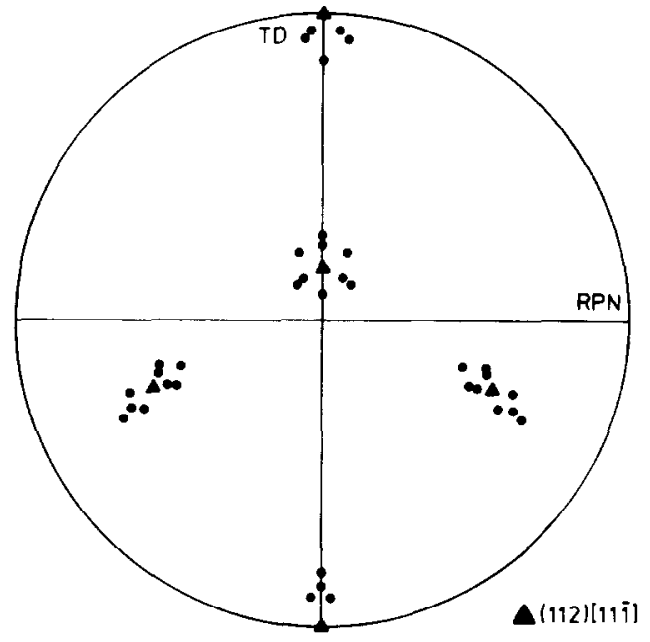

Fig. 8. Stereographic projection showing $\langle 111\rangle$ poles of orientations measured at one side of grain boundary in $\{110\}\langle 112\rangle$ rolled bicrystal, plane of projection perpendicular to rolling direction.

ture of the grain-boundary region in a specimen of the $\{112\}\langle 111\rangle$ plane-strain deformed bicrystal, which has been annealed for $20 \mathrm{~s}$ at $360 \mathrm{C}$. In Fig. 11 a photograph is presented of a specimen of the $\{112\}\langle 111\rangle$ rolled bicrystal annealed somewhat longer than the specimen in Fig. 9, namely $30 \mathrm{~s}$ at $400^{\circ} \mathrm{C}$.

In both photographs grains of considerable size can be observed that overlap the "old" boundary and are surrounded by deformed matrix (see for instance

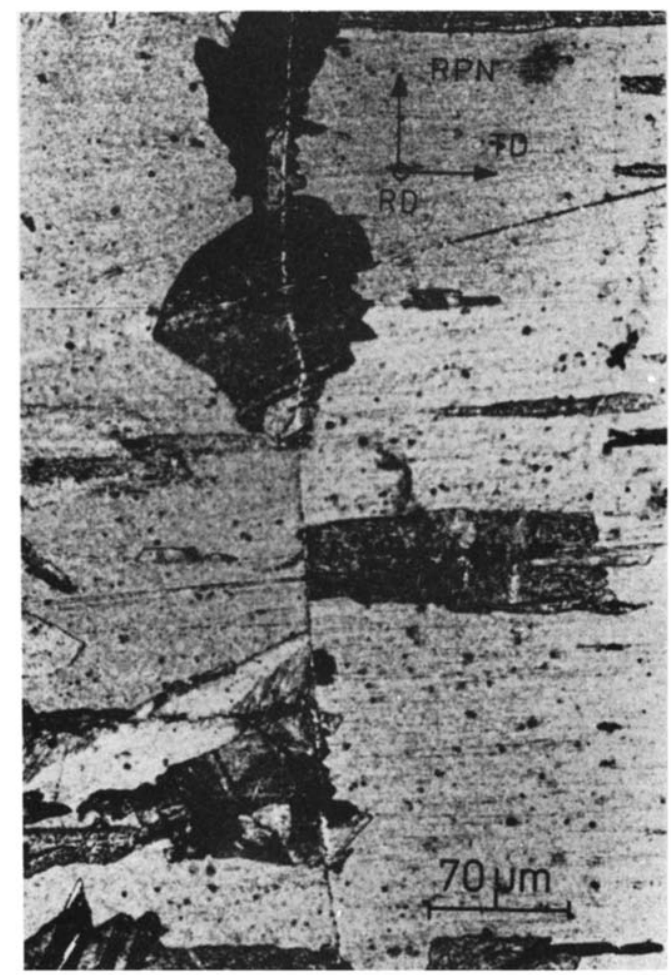

Fig. 9. Photomicrograph of grain boundary area of $49.8 \%$ rolled $\{112\}\langle 111\rangle$ bicrystal annealed for $15 \mathrm{~s}$ at $400 \mathrm{C}$; viewing plane perpendicular to rolling direction. 
grain $1 / 2$ and grain $7 / 8$ in Fig. 10). Even without orientation measurements one can easily see, that, for instance, orientations $3 / 4$ and $18 / 19$ in Fig. 11 belong to the same new grain although situated at different sides of the former boundary, because annealing twins in the grain interior cross the obviously eliminated boundary undefiected. This is indeed confirmed by orientation measurements. The fact that the former boundary is still visible in the recrystallized grains is probably the result of some kind of decoration of the original grain boundary and no orientation effect in the sense that there would be an orientation difference across the original boundary. Optical microscopical observations gave some indication that impurities might be the cause of this etching effect.

Next to the photographs of Figs 10 and 11 the grain boundary has been copied and the recrystallized grains that have nucleated most likely at these boundaries have been drawn. The orientations of the deformed-matrix parts are given with respect to the viewing plane.

In the $\{110\}\langle 112\rangle$ deformed bicrystals the grain boundary did form a predominant nucleation site. In

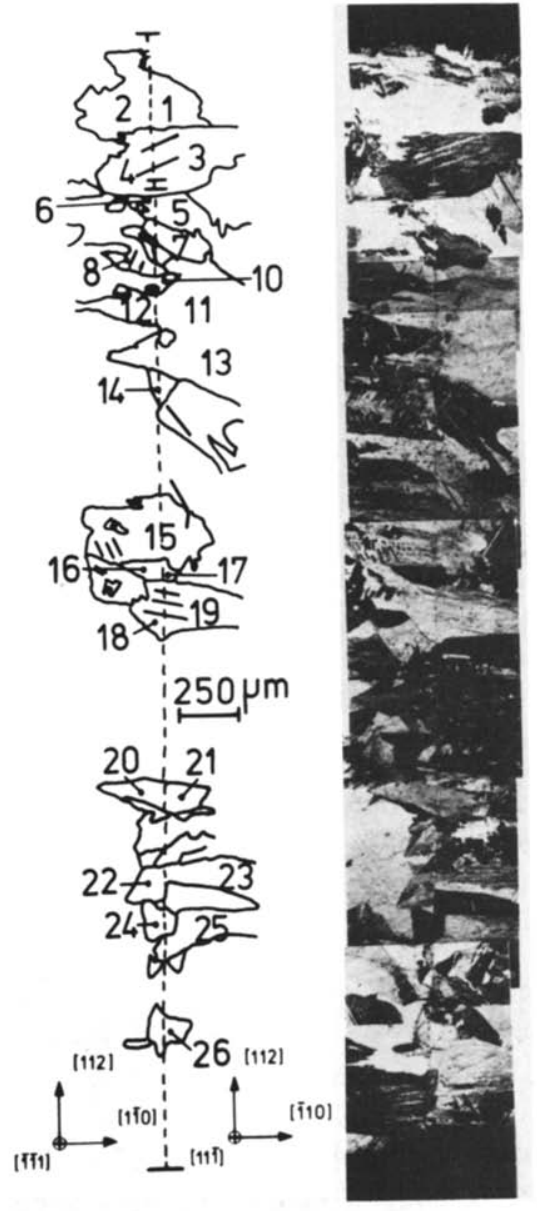

Fig. 10. Photomicrograph of grain-boundary area of $41.6 \%$ plane-strain deformed $\{112\}\langle 111\rangle$ bicrystal annealed for $20 \mathrm{~s}$ at $360^{\circ} \mathrm{C}$; viewing plane is compression plane.

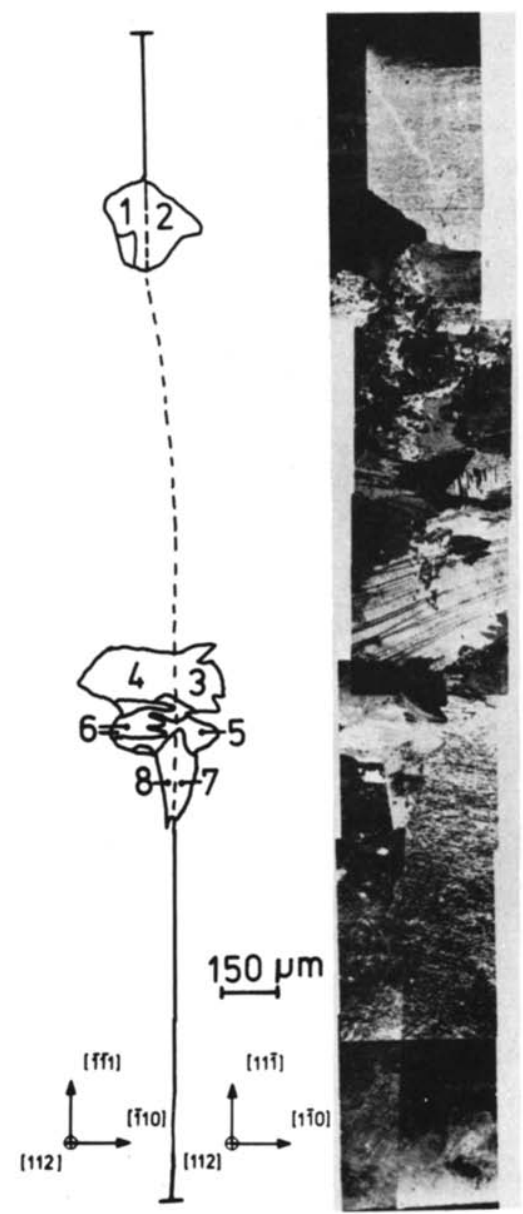

Fig. 11. Photomicrograph of grain-boundary area of $49.8^{\circ}$ rolled $\{112\}\langle 111\rangle$ bicrystal annealed for $30 \mathrm{~s}$ at $400 \mathrm{C}$ viewing plane perpendicular to rolling direction.

specimens of the plane-strain deformed bicrystal, however, the recrystallization was not uniform along the boundary. The recrystallized parts were found at the edge of the specimens. In Fig. 12 an edge side of such a specimen is shown (heat treated at $320^{\circ} \mathrm{C}$ for $400 \mathrm{~s}$ ).

At the same time the strong tendency to annealing. twin formation is conspicious. Sometimes these twins have sizes of less than $5 \mu \mathrm{m}$. Figure 13, finally, contains a representative section of a $\{110\}<112\rangle$ rolled bicrystal (heat treatment: $150 \mathrm{~s}$ at $400^{\circ} \mathrm{C}$ ). Unlike the specimens of the plane-strain deformed bicrystal, the annealing treatment in these specimens caused recrystallization along the full length of the grain boundaries.

Because this investigation was aimed at finding the role of a specific grain boundary in the recrystallization process, orientation measurements were done only on those grains that presumedly have nucleated at the boundary. They are indicated in the drawings next to the photographs. Tables $2-4$ list the results of these orientation determinations. In the first column of these tables the direct computer output of the orientation calculation from the Laue patterns is 


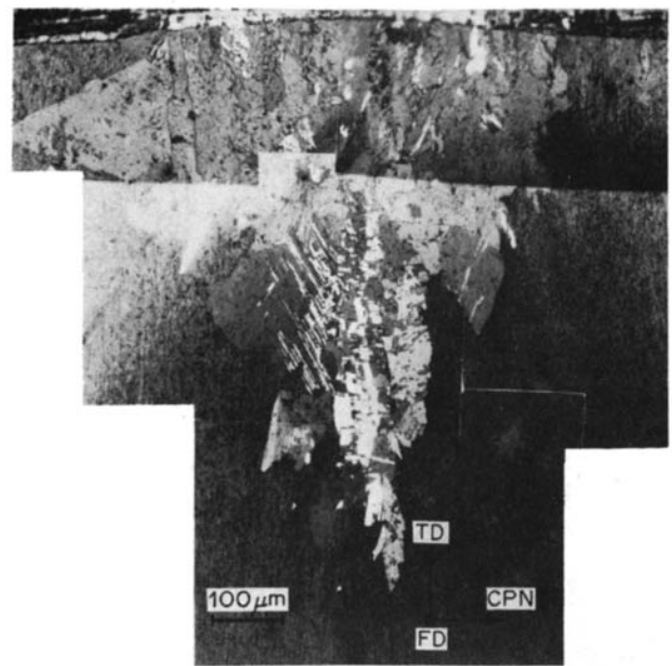

Fig. 12. Photomicrograph of $57.5^{\circ}$ oplane-strain deformed $\{110\}\langle 112\rangle$ bicrystal showing recrystallization along grain boundary at edge of specimen; viewing plane perpendicular to free direction.

given. Because this first column conveys hardly anything, the results of the interpretation are entered in a second column. In a third column the deviations of the orientations from the ones in the column of identification is given in terms of "disorientation angle". "Disorientation" is defined by the smallest angle of rotation that out of the 24 possible ones transforms orientations into each other [14].

The interpretation as given in the second column will be discussed in more detail in the next section. Anticipating on this discussion, one can, however, perceive that the orientations of the recrystallized grains could be traced back to having relationships with the matrix orientation but for the greater part with orientations predicted by the $\langle 112\rangle$-slip nucleation mechanism. In either case the fact that copper forms annealing twins most readily has been taken into full account.

\section{DISCUSSION}

\subsection{The grain boundary as nucleation site}

Although one never can decide whether the nucle-

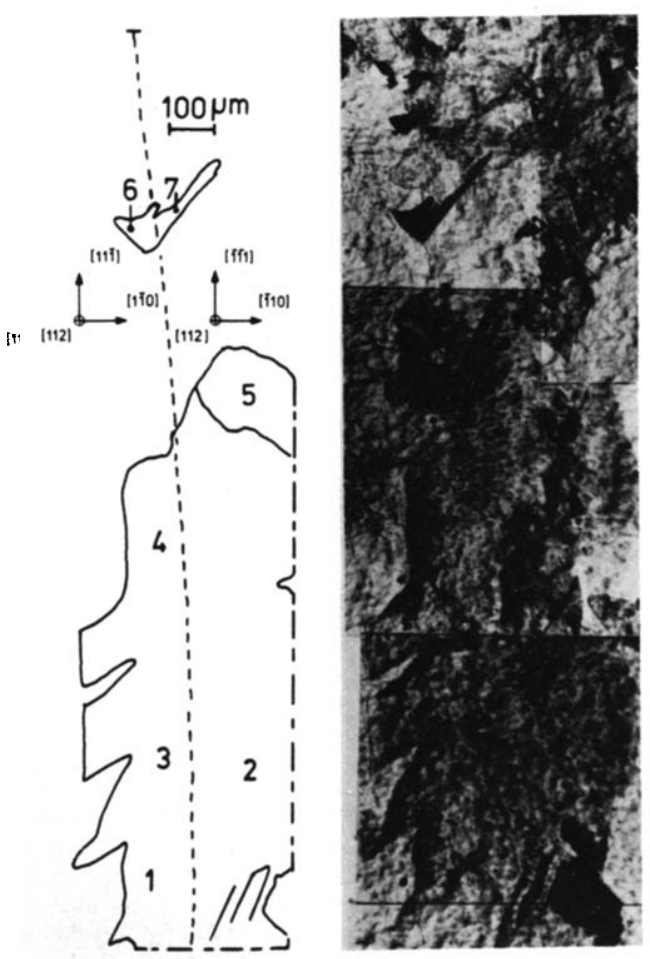

Fig. 13. Photomicrograph of grain-boundary area of $57.5 \%$ rolled $\{110\}\langle 112\rangle$ bicrystal annealed for $150 \mathrm{~s}$ at $400^{\circ} \mathrm{C}$; viewing plane perpendicular to rolling direction.

ation takes place exactly at a particular spot, the photographs that present examples of the recrystallization behaviour in the bicrystals strongly suggest that the grain boundary may be considered as a nucleation site. Photographs and tables strengthen this assumption. Apparently, the deformation in $\{112\}\langle 111\rangle$ bicrystals leads also to nucleation sites in the matrices themselves, as opposed to $\{110\}\langle 112\rangle$ bicrystals. This behaviour could be in good agreement with the fact that the "stored energy" in a $\{112\}\langle 111\rangle$ deformed matrix is higher than that in $\{110\}\langle 112\rangle$ deformed crystals.

In the $\{110\}\langle 112\rangle$ plane-strain deformed bicrystals no recrystallization in the matrix could be detected. Although apparently the grain boundary is favoured as nucleation site, the outmost parts of the grain

Table 2. Orientation of recrystallized grains in the plane-strain deformed $\{112\}\langle 111\rangle$ bicrystal

\begin{tabular}{|c|c|c|c|c|c|c|}
\hline Grain & (references & $\begin{array}{l}\text { Orientation } \\
\text { ression pla }\end{array}$ & direction) & $\begin{array}{c}\text { Identified } \\
\text { with }\end{array}$ & $\begin{array}{c}\text { Disorientation angle } \\
\qquad \psi_{\text {min }}\end{array}$ & Remarks \\
\hline $1: 2$ & $\begin{array}{r}0.7309 \\
0.6835\end{array}$ & $\begin{array}{r}0.6284 \\
-0.6793\end{array}$ & $\begin{array}{l}-0.2664 \\
-0.2670\end{array}$ & $(432)\{221]$ & $3.9^{-}$ & $\begin{array}{l}\text { twin of } \\
(210)[00 \mathrm{~T}]\end{array}$ \\
\hline $3 / 4$ & $\begin{array}{l}-0.8516 \\
-0.1094\end{array}$ & $\begin{array}{r}-0.5194 \\
0.0306\end{array}$ & $\begin{array}{r}-0.0702 \\
0.9935\end{array}$ & $(210)[001]$ & $7.4^{\mathrm{c}}$ & \\
\hline 5 & $\begin{array}{r}0.7174 \\
-0.6887\end{array}$ & $\begin{array}{l}0.5430 \\
0.6389\end{array}$ & $\begin{array}{l}0.4364 \\
0.3428\end{array}$ & $(\mathbf{4 3 2})[22 I]$ & 8.6 & $\begin{array}{l}\text { twin of } \\
(210[001]\end{array}$ \\
\hline 6 & $\begin{array}{r}0.9928 \\
-0.1014\end{array}$ & $\begin{array}{l}0.1192 \\
0.8574\end{array}$ & $\begin{array}{l}0.0121 \\
0.5045\end{array}$ & $\begin{array}{c}\text { twin of } \\
(\mathbf{4 3 2})[22 \mathrm{2}]\end{array}$ & $4.6:$ & $\begin{array}{l}\text { 2nd-order } \\
\text { twin of } \\
(210)[001]\end{array}$ \\
\hline 788 & $\begin{array}{l}-0.8882 \\
-0.1964\end{array}$ & $\begin{array}{r}-0.4317 \\
0.0432 \\
\end{array}$ & $\begin{array}{r}-0.1574 \\
0.9796\end{array}$ & $(210)[001]$ & 11.6 & \\
\hline
\end{tabular}

The values calculated by the computer program are permutated to one system of references in the column of the identification 
Table 3 . Orientations of recrystallized grains in the rolled $\{112\}<111\rangle$ bicrystal

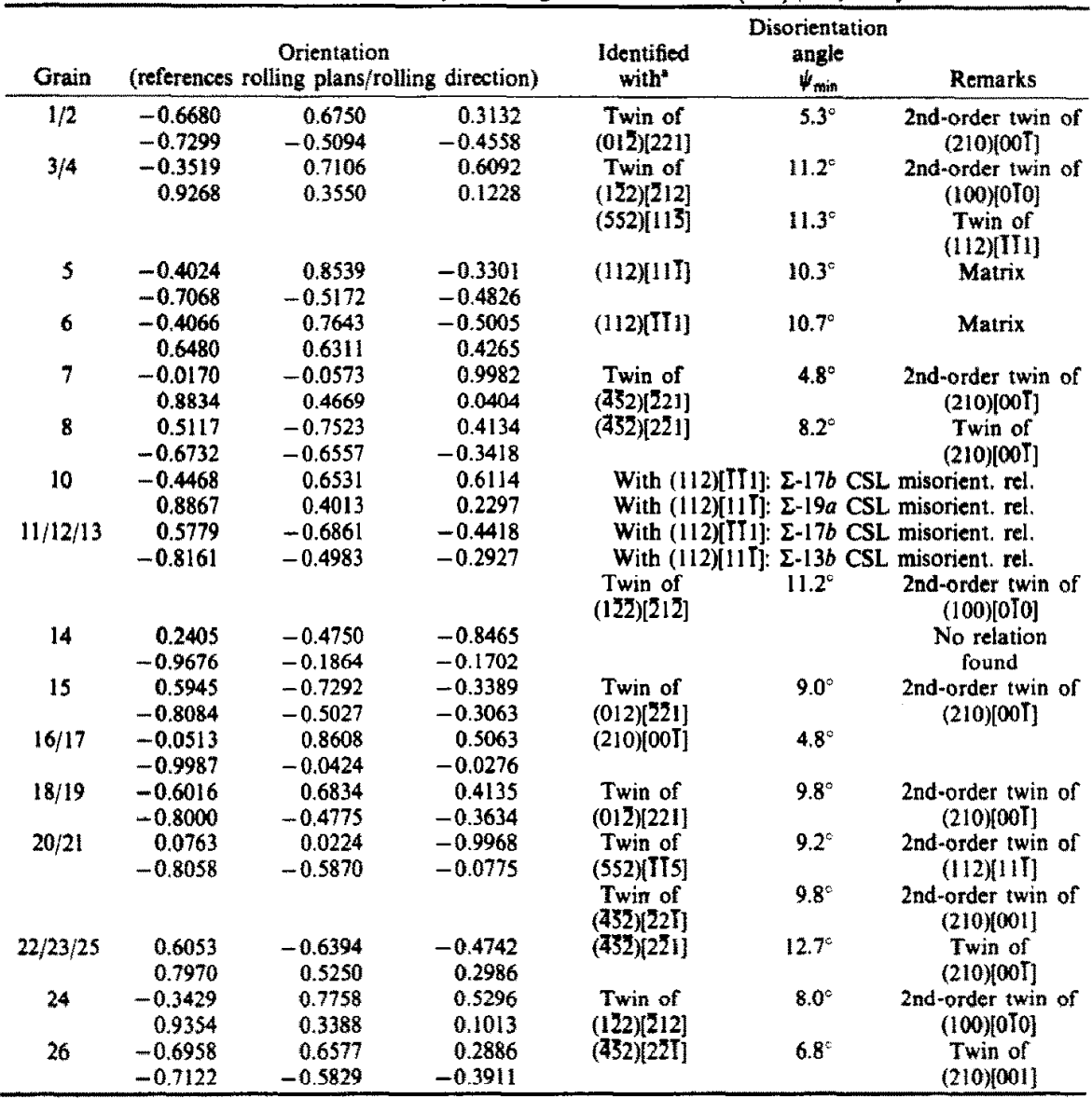

The values calculated by the computer program are permutated to one system of references in the column of the identification.

Table 4 . Orientation of recrystallized grain in the rolled $\{110\}<112\rangle$ bicrystal

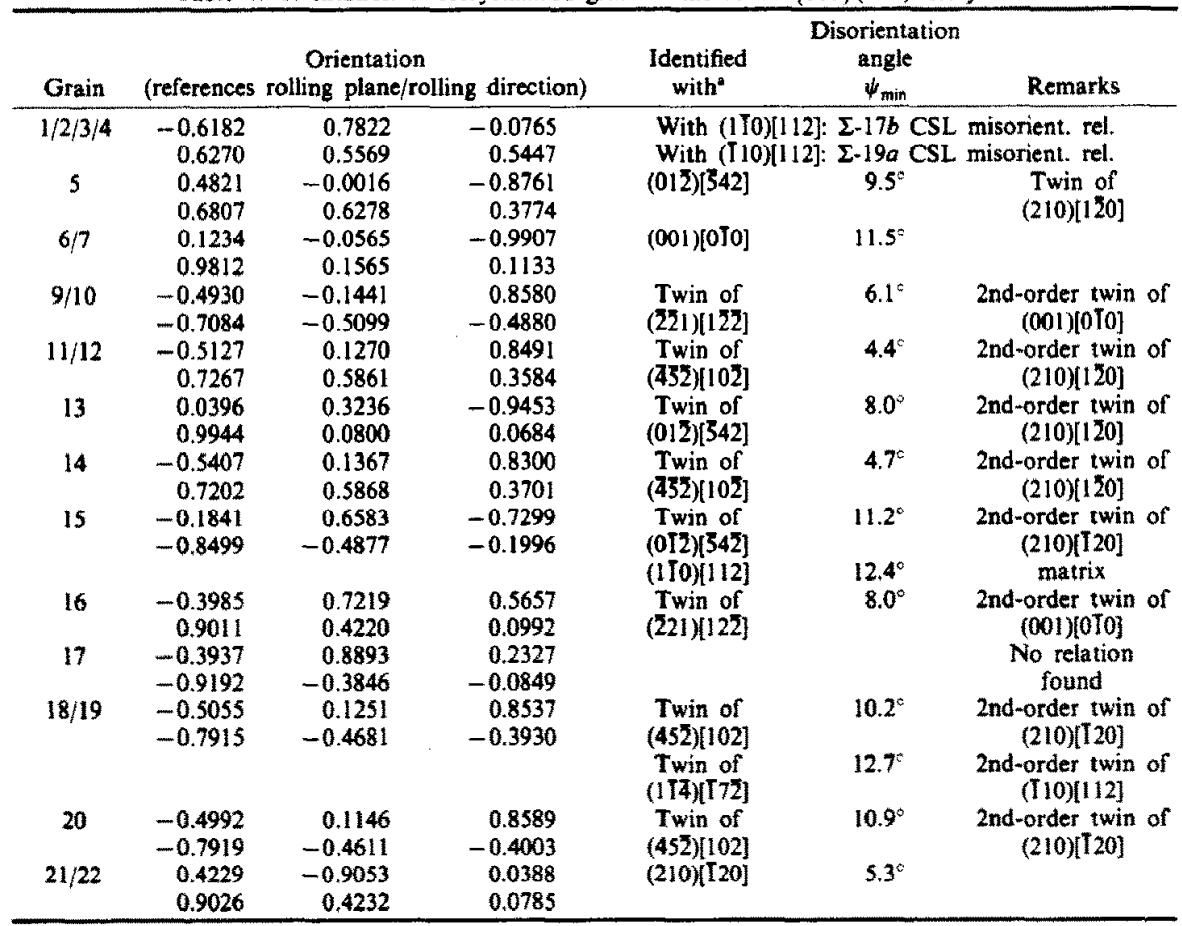

The values calculated by the computer program are permutated to one system of references in the column of the identification, 
boundary were observed to recrystallize predominantly. This phenomenon can, however, be understood in the following way. It is well-known from single crystals with $\{110\}\langle 112\rangle$ orientations [15] that a crystallographically determined shape change takes place during deformation (an initial rectangle is converted into a parallelogram when viewed at the compression plane of the crystal). Since both bicrystal parts are in twin position, having the twin plane parallel to the compression plane, their shape changes are opposite at either side of the boundary and will produce a torsion in this boundary plane. $A$ mathematical treatment is given by Noll et al. [16], who investigated deformation behaviour of $\{110\}\langle 112\rangle$ copper bicrystals. In a bicrystal with the same deformation geometry as in the present investigation the incompatibility in shape change was demonstrated.

Because the shear component $\varepsilon_{x y}(x=$ free direction, $y=$ transversal direction) is reversed at the grain boundary, additional shear stresses, $\tau_{x y}$, are induced at either side, having opposite signs. Parallel to this boundary their magnitude decreases from transversal plane towards the middle. At this point the direction of the shear stress is reversed and increases again. It will be clear now that the resulting torsion will have its maximum near the transversal planes, where preferential nucleation sites will be created. Nucleation at these spots is clearly demonstrated in the photograph in Fig. 12.

To prevent this phenomenon, the bicrystals were thereupon rolled embedded in polycrystalline copper, which also gives a better approximation of the deformation behaviour in polycrystalline material. The annealing treatments in the $\{110\}\langle 112\rangle$ bicrystals deformed in this way did not cause preferential nucleation sites at particular parts of the grain boundary. The fact that Noll et al. measured a steep increase in hardness in the immediate surrounding of the grain boundary in the work cited earlier [16] is in full agreement with the fact that the bicrystal grain boundary indeed acts as a nucleation site. This increase in hardness is explained by activation of additional deformation mechanisms, like formation of microbands directly near the grain boundary. Over these bands a small lattice totation is accomplished as a result of shear stresses induced by the shape-change incompatibility. The formation of subgrains and the spread in orientations as observed in the present investigations are very similar.

As for the $\{112\}\langle 111\rangle$ bicrystals, the deformation must lead to a similar microstructure and spread in orientations, since the chosen deformation geometry also brings incompatibility in shape change with it.

\subsection{Orientations of recrystallized grains}

According to many authors [7, 17-19], nucleation of recrystallization textures in f.c.c. metals can be described by nucleation from orientations present in the deformed matrix, followed by repeated growth accidents that form annealing twins in case of lowSFE f.c.c. metals. This twinning sequence should cease when an orientation with good growth capacity has been formed. In case of copper this condition is the well-known $30^{\circ}-40^{\circ}\langle 111\rangle$ orientation relationship. Therefore, the orientations of the grains recrystallized at the grain boundary have been analysed with respect to these conditions, the spread in the matrix having been taken into account.

In analysing orientations twinning up to the second order of matrix orientations was considered and deviations of $10-15^{\circ}$ of initial orientations were allowed. To this end twin chains up to the second order were computed for each orientation; subsequently the disorientation with the matrix orientations (rotation angle $\psi_{\min }$ ) was calculated for each of the elements in this chain (2l per orientation). If the angle $\psi_{\min }$ is smaller than $10-15^{\circ}$, the orientation in question is considered to be a possible matrix orientation that forms the basis for annealing twinning leading to the observed orientation.

In the $\{112\}<111\rangle$ plane-strain deformed bicrystal no matrix orientations could be traced in this way. In the $\{112\}\langle 111\rangle$ rolled crystal a few orientations could be found that may have nucleated from matrix orientations. The orientation of grains 5 and 6 (Table 3) are noteworthy. These orientations strongly suggest that these grains had nucleated at the very boundary, as they have the orientation of that part of the bicrystal they do not grow into. For instance, grain number 5 in Fig. 11 has approximately the (112)[111] orientation, whereas its growth proceeds in the (112)[TT1] matrix].

The major part of the orientations, however, could not be traced back to matrix orientations. Therefore all nucleation mechanisms in which orientations present in the deformed matrix play a decisive role fail to explain the observed orientations.

On the basis of the orientation analysis it must be concluded that recrystallized grains have developed with orientations completely different from the matrix orientations. Since copper is involved, subsequent twinning may have changed the orientations initially developed. A mechanism that creates nuclei with such completely different orientations is one that eliminates a (110) boundary as a result of cooperative $\langle 112\rangle$ slip. This mechanism has been the subject of many previous publications $[1,2,20-24]$. It predicts $\{100\}\langle 001\rangle$ and $\{210\}\langle 001\rangle$ orientations in case of $\{112\}\langle 111\rangle$ matrix orientations, $\{100\}\langle 001\rangle$ and $\{210\}\langle 120\rangle$ orientations in case of $\{110\}\langle 112\rangle \mathrm{ma}$ trix orientations. Tables $2-4$ already disclosed the fact that the remaining part of the orientations could have originated from this mechanism. In its basic form it requires the presence of nearly twins of the deformation texture next to each other, in order to have situation in which the $\langle 112\rangle$-slip mechanism operating at both sides of the boundary produces the same orientation, thus eliminating the boundary. The driving force for the mechanism is the elimination of 
a high-energy boundary, like the incoherent (110) twin boundary.

It will be clear now that the bicrystal combinations used in the present investigations fulfil these requirements explicitly. In an analysis of the crystallographic aspects of this mechanism Heller [25] demonstrated that the requirement of small deviations from the exact $\{112\}\langle 111\rangle$ and $\{110\}<112\rangle$ twinned orientations necessary to let the $\langle 112\rangle$-slip produce identical orientations at both sides of the grain boundary leads to resulting orientations that might slightly differ from the mentioned $\{100\}\langle 001\rangle,\{210\}\langle 001\rangle$ and $\{210\}\langle 120\rangle$ orientations (upto approximately $10^{\circ}$ ). So, orientations of a nucleus that are within about $10^{\circ}$ from $\{100\}\langle 001\rangle,\{210\}\langle 001\rangle$ and $\{210\}\langle 120\rangle$ can be nucleated by the $\langle 112\rangle$-slip nucleation mechanism.

In order to analyse the orientations of the recrystallized grains with respect to the $\langle 112\rangle$-slip nucleation mechanism and its resulting orientations, the same procedure was followed as in the case of analysing matrix relations. So twin chains were calculated and "disorientation angles" were determined. To simplify the calculations, the deviations of each element in these chains from $\{100\}\langle 001\rangle$, $\{210\}\langle 001\rangle$, or $\{210\}\langle 120\rangle$ were computed. When the angle $\psi_{\min }$ was smaller than about $10^{\circ}$, the orientation in question was considered to arise from the $\langle 112\rangle$-slip mechanism and to form the basis for annealing twinning, leading to the observed orientations (see Tables 2-4). In Fig. 14 a stereographic projection is given which is a representative example of the results of such calculations $(\langle 100\rangle$ poles of nucleus orientations have been plotted). Recrystallized grains from the specimen of the $\{112\}\langle 111\rangle$ rolled bicrystal are concerned (see also Table 3). Note that all orientations lie within the $10^{\circ}$

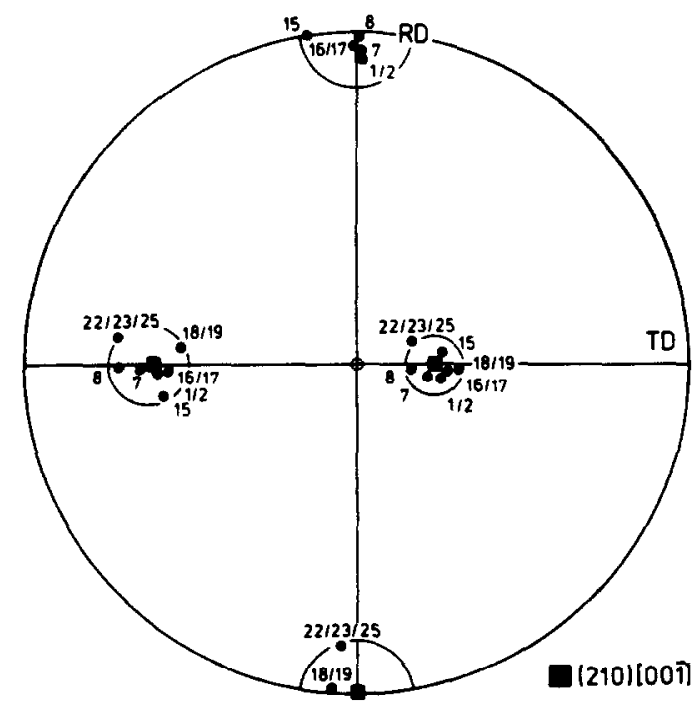

Fig. 14. Stereographic projection showing $\langle 100\rangle$ poles of recrystallized grains nucleated in orientations near (210)[001] (rolled $\{112\}\langle 111\rangle$ bicrystal). circles about the $\langle 100\rangle$ poles of the $(210)[00 \bar{I}]$ orientation. Tables $2-4$, finally, clearly demonstrate to which extent the $\langle 112\rangle$-slip nucleation mechanism might have played a role.

Summarizing, the discussed observations point to a decisive role of the $\langle 112\rangle$-slip nucleation mechanism, in which the driving force for nucleation is found in the energy decrease at the incoherent twin boundaries. This is supported by $\mathrm{X}$-ray stress measurements [25]. These measurements show that upon annealing these strains are relaxated by plastic deformation which involves movement of $\langle 112\rangle$ dislocations in directions required for the creation of nuclei by the $\langle 112\rangle$-slip nucleation mechanism. Therefore the argument of many authors that it is questionable whether the $\langle 112\rangle$ dislocations move in the correct direction proves to be wrong, because the relaxation of the stress fields (responsible for the elastic strains) will cause the dislocations to move in the correct direction.

\subsection{Final remarks}

In many papers recrystallization textures are interpreted on the basis of growth selectivity. From this point of view the nucleation of recrystallization textures plays a role of secondary importance, because the ultimate recrystallization textures will be determined by the fastest growing grains having special orientation relationships with the matrix they grow into. Nuclei not satisfying the special orientation relationship will not experience growth to a large extent, and will therefore be hardly perceptable in the recrystallization textures. The orientation relationship for these fastest growing grains in case of pure copper is found to be a $30^{\circ}\langle 111\rangle$ rotation relationship [26]. In other low-SFE metals also a favouring for growth on the basis of a $37^{\circ}\langle 100\rangle$ rotation [27] or $35^{\circ}\langle 110\rangle$ rotation is found [28]

In the present investigations no such relationships could be detected, although grains with considerable grain size were observed and analysed with respect to these conditions. The observation that grains initially unfavourable for growth will change their orientations by twinning until a $30^{\circ}\langle 111\rangle$ relationship is reached could be demonstrated neither $[17,26]$.

On the other hand, in a few cases the analyses did yield rotational orientation relationships between recrystallized grains and matrix that might be significant. Grain 1/2/3/4 in the photograph in Fig. 13 is the best example of these relationships, which is elucidated in Fig. 15 (see also Tables 2-4). This figure presents a stereographic projection of the $\langle 100\rangle$ poles of the orientations of grain $1 / 2 / 3 / 4$ together with both matrix orientations of the bicrystal. The orientations have been projected on the plane perpendicular to the RD.

The recrystallized grain has a $\langle 110\rangle$ pole almost in common with the $\langle 110\rangle$ rolling-plane normal of both parts of the $\{110\}\langle 112\rangle$ bicrystal (deviation $6.2^{\circ}$, but lying within the spread). In order to get the orien- 


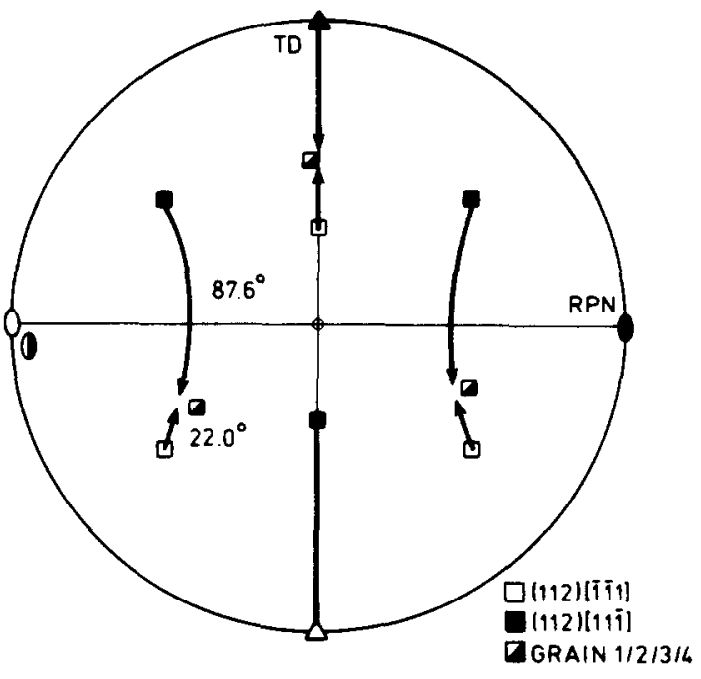

Fig. 15. Representations of orientation relationship of recrystallized grain $1 / 2 / 3 / 4$ in the $\{110\}\langle 112\rangle$ rolled bicrystal with both matrix parts; plane of projection perpendicular to rolling direction.

tation of the recrystallized grains for the (112)[i]1] orientation, a rotation about this nearly common $\langle 110\rangle$ axis of $22^{\circ}$ is needed, for the (112)[11T] orientation a rotation of $87.6^{\circ}$ (indicated in Fig. 15). The axes as well as the rotation angles are very near to the CSL misorientation relations (coincident-site lattice). The $87.6^{\circ}$ rotation is near to the $86.6^{\circ}$ rotation about the $\langle 110\rangle$ axis needed for a $\Sigma-17 b$ CSL misorientation relation, the 22 rotation is near to the $26.5^{\circ}$ rotation needed for a $\Sigma-19 a$ CSL misorientation relation. Because of the considerable size of this grain one may think of an explanation from the growth point of view. Near-CSL relationships proved more often to yield good growth capabilities (a $38^{\circ}\langle 111\rangle$ rotation is near the $\Sigma=7$ coincidence, a $37^{\circ}\langle 100\rangle$ rotation is near the $\Sigma=5$ coincidence). Up to now, however, the rotations in question are not observed as to yield extreme growth capabilities.

If one views this observation from the nucleation standpoint, the mechanism is obscure, but it might be an indication of a more general nucleation mechanism that could be described as follows. A deformed grain boundary splits into two boundaries on annealing if the following conditions are fulfilled:

(i) a local concentration of stored energy at the boundary;

(ii) the orientation between the two new boundaries is such that these new boundaries are low-energy boundaries or, in other words, the new orientation has formed CSL lattices with both orientations on either side of the original boundary.

In this formulation the $\langle 112\rangle$-slip nucleation mechanism would only be a special case leading to $\Sigma-17$ boundaries at an imperfect (110) boundary between two twin-related crystals [29]. Dissociation of highangle boundaries into a twin and another low-energy boundary, as observed by Goodhew et al. [30], would support this assumption. Moreover, the formation of recrystallization twins would also fall in this category. On the basis of the present experiments, however, this formulation is rather speculative; a larger number of recrystallization experiments at different grain boundaries is needed to justify it.

\section{CONCLUSIONS}

1. Recrystallization experiments on deformed $\{112\}\langle 111\rangle$ and $\{110\}\langle 112\rangle$ copper bicrystals, having an incoherent (110) twin boundary in either case, demonstrated that the nucleation of recrystallization at the grain boundary must be considered significant.

2. Grains nucleated at the houndary can be divided into three groups; in consecutive frequency of their orientations:

grains with orientations originating from a 〈112〉-slip nucleation mechanism

grains with matrix orientations

grains with near-CSL misorientation relations with the matrix.

In all cases the orientations may change by annealing-twin formation.

Acknowledgements-Grateful thanks are due to $\mathrm{M}$. J. ten Bouwhuijs, W. H. J. Bruis, H. Koster and A. M. Nijssen for their helpful discussion and experimental assistance. This work is part of the research programme of the research group "Metals FOM-TNO" of the "Stichting voor Fundamenteel Onderzoek der Materie" (Foundation for Fundamental Research of Matter, FOM) and was also made possible by financial support from the "Nederlandse Organisatie voor Zuiver-Wetenschappelijk Onderzoek (Netherlands Organization for the Advancement of Pure Research, ZWO).

\section{REFERENCES}

1. C. A. Verbraak, Acia metall. 6, 580 (1958)

2. C. A., Verbraak, Ph. D. thesis, Univ. of Delft, The Netherlands (1959).

3. I. L., Dillamore, P. L., Morris, C. J. E. Smith and W. B. Hutchinson, Proc. R. Soc. A 329, 405 (1972).

4. I. L. Dillamore and H. Katoh, Metal. Sci. 8, 73 (1974).

5. J. E. Bailey and P. B. Hirsch, Proc. R. Soc. A 267, 11 (1962).

6. B. F. Peters. Metall. Trans. 4, 757 (1973)

7. S. Hoekstra, J. W. H. G. Slakhorst and J. Huber, Acta metall. 25, 395 (1977).

8. R. K. Ray, W. B. Hutchinson, F. M. C. Besag and R. E. Smallman, J. Microscopy 7, 217 (1973/2).

9. A. A. Ridha and W. B. Hutchinson, in Proc. Sixth Int. Conf. on Textures of Materials (edited S. Nagashima), p. 112. Iron and Steel Inst., Japan (1981).

10. N. J. Long and R. E. Smallman, in Proc. Seventh Eur. Congr. Electron Microscopy (Eurem 80 ) (edited by $\mathrm{P}$ Bredero and G. Boom), Vol. 4, p. 356. North-Holland, Amsterdam (1980).

11. T. Noda, B. Plege and J. Grewen, in Proc. Fifth Int Conf. on Textures of Materials (edited by $\mathbf{G}$. Gottstein and K. Lücke), Vol, 1, p. 443. Springer, Berlin (1978)

12. F. J. ter Avest and J. A. Klostermann, J. Phys. E, Sci. Instrum. 2, 950 (1969).

13. R. E. Bauer, H. Mecking and K. Lücke, Mater. Sci. Engng 27, 163 (1977). 
14. G. Ibe and K. Lücke, Texture 1, 87 (1973).

15. W. Noll and W. Heye, Z. Metallk. 68, 205 (1977).

16. W. Noll and W. Heye, Z. Metallk. 68, 297 (1977/2).

17. P. J. T. Stuitje and G. Gottstein, in Proc. Fifth Int. Conf. on Textures of Materials (edited by G. Gottstein and K. Lücke), Vol. 1, p. 511. Springer, Berlin (1978).

18. K. H. Virnich, Ph.D. thesis, Univ. of Aachen, F.R.G. (1979)

19. P. J. Wilbrandt and P. Haasen, Z. Metallk. 71, 385 (1980)

20. C. A. Verbraak, Acta metall. 8, 65 (1960).

21. C. A. Verbraak, in Proc. Fifth Int. Conf. on Textures of Materials (edited by G. Gotrstein and K. Lücke), Vol 1, p. 111. Springer, Berlin (1978).

22. J. W. H. G. Slakhorst, Acta metall. 23, 301 (1975).

23. J. W. H. G. Slakhorst, Ph.D. thesis, Twente Univ. of Technology, The Netherlands (1977).
24. H. P. Kneijnsberg, J. W. H. G. Slakhorst and C. A. Verbraak, Acta metall. 27, 101 (1979).

25. H. W. F. Heller, Ph.D. thesis, Twente Univ. of Technology, The Netherlands (1982).

26. D. Zabardjadi, Ph.D. thesis, Univ. of Aachen, F.R.G. (1976).

27. K. H. Virnich and $\mathrm{K}$. Lücke, in Proc. Sixth Int. Conf. on Textures of Materials (edited by $\mathrm{S}$. Nagashima), p. 560. Iron and Steel Inst. Japan (1981/2).

28. U. Schmidt, K. Lücke and J. Pospiech, in Texture and the Properties of Materials, Proc. Fourth Int. Conf. on Texture (edited by G. J. Davies et al.), p. 147. The Metals Society, Cambridge (1975).

29. C. A. Verbraak, in Proc. Sixth Int. Conf, on Textures of Materials (edited by $\mathrm{S}$. Nagashima), p. 98. Iron and Steel Inst. Japan (1981).

30. P. J. Goodhew, T. Y. Tan and R. W. Balluffi, Acta metall. 26, 557 (1978). 